\title{
TITLE:
}

\section{$<$ Notes> Genito-genital Rubbing among the Chimpanzees of Mahale and Bossou}

\section{$\operatorname{AUTHOR}(\mathrm{S})$ :}

Zamma, Koichiro; Fujita, Shiho

\section{CITATION:}

Zamma, Koichiro ... [et al]. < Notes> Genito-genital Rubbing among the Chimpanzees of Mahale and Bossou. Pan Africa News 2004, 11(2): 5-8

ISSUE DATE:

2004-12

URL:

http://hdl.handle.net/2433/143444

RIGHT:

Copyright (C) Pan Africa News. 
<NOTES>

Genito-genital rubbing among the chimpanzees of Mahale and Bossou

Koichiro Zamma ${ }^{1}$, Shiho Fujita ${ }^{2}$

${ }^{1}$ Primate Research Institute, Kyoto University

${ }^{2}$ Faculty of Applied Biological Sciences, Gifu University

\section{Introduction}

Genito-genital (GG) rubbing, which is known as one of the unique behaviors of bilias (bonobo: Pan paniscus), has the following characteristics: two females assume a ventro-vental or ventrodorsal position and the younger female thrusts her pelvis (Yerkes Regional Primate Research Center, Atlanta ${ }^{1}$ ), or two females embrace ventro-ventrally and rub each other's sexual skin together (Wanba, Republic of Zaire ${ }^{2,3}$ ). In captivity, chimpanzees (Pan troglodytes) were 


\begin{tabular}{|c|c|c|c|c|c|c|c|c|}
\hline \multirow{3}{*}{$\frac{\text { No }}{1}$} & \multirow{3}{*}{$\frac{\text { Date }}{\text { Jan } 14}$} & \multirow{3}{*}{$\begin{array}{l}\text { Time - } \\
9: 08\end{array}$} & \multicolumn{3}{|c|}{ Name (Estrous phase ") } & \multirow{3}{*}{$\begin{array}{c}\begin{array}{c}\text { Activity before } \\
\text { GG Rubbing }\end{array} \\
\text { moving }\end{array}$} & \multirow{3}{*}{$\frac{\text { Position }}{\text { DD-1 }}$} & \multirow{3}{*}{$\frac{\text { Rubbing }^{c}}{-}$} \\
\hline & & & \multicolumn{2}{|c|}{ Female 1} & Female 2 & & & \\
\hline & & & Vel & $(-9 / 3)$ & $(+1 / 1)$ & & & \\
\hline 2 & Jan 14 & $11: 57$ & Vel & $(-9 / 3)$ & $(+1 / 1)$ & moving & DD-2 & - \\
\hline 3 & Jan 15 & $8: 00$ & Vel & $(-8 / 3)$ & $(+2 / 1)$ & moving & DD-2 & - \\
\hline 4 & Jan 15 & $11: 52$ & Vel & $(-8 / 3)$ & $(+2 / 1)$ & moving & DD-1 & - \\
\hline 5 & $\operatorname{Jan} 15$ & $11: 57$ & Vel & $(-8 / 3)$ & $(+2 / 1)$ & moving & DD-1 & - \\
\hline 6 & $\operatorname{Jan} 15$ & $12: 01$ & Vel & $(-8 / 3)$ & $(+2 / 1)$ & moving & DD-1 & - \\
\hline 7 & $\operatorname{Jan} 15$ & $12: 04$ & Vel & $(-8 / 3)$ & $(+2 / 1)$ & moving & DD-1 & - \\
\hline 8 & $\operatorname{Jan} 15$ & $17: 30$ & Vel & $(-8 / 3)$ & $(+2 / 1)$ & moving & DD-1 & - \\
\hline 9 & $\operatorname{Jan} 16$ & $8: 42$ & Vel & $(-7 / 3)$ & $(+3 / 1)$ & moving & unsuccess $^{b}$ & \\
\hline 10 & Jan 16 & $8: 57$ & Vel & $(-7 / 3)$ & Nina $(\eta / 2)$ & feeding & VD & + \\
\hline 11 & $\operatorname{Jan} 19$ & $12: 30$ & Vel & $(-3 / 3)$ & Nina $(\eta / 3)$ & resting & VD & + \\
\hline 12 & Jan 19 & $16: 32$ & Vel & $(-3 / 3)$ & Nina $(2 / 3)$ & feeding & unsuccess $^{b}$ & \\
\hline 13 & $\operatorname{Jan} 20$ & $7: 32$ & Vel & $(-2 / 3)$ & Vuavua $(? / 1)$ & moving & DD-1 & - \\
\hline 14 & $\operatorname{Jan} 20$ & $8: 11$ & Vel & $(-2 / 3)$ & Nina (?/3) & resting & unsuccess ${ }^{\text {b }}$ & \\
\hline 15 & $\operatorname{Jan} 20$ & $8: 13$ & Vel & $(-2 / 3)$ & Nina $(2 / 3)$ & resting & VD & + \\
\hline 16 & $\operatorname{Jan} 20$ & $8: 26$ & Vel & $(-2 / 3)$ & Nina $(2 / 3)$ & resting & unsuccess $^{b}$ & \\
\hline 17 & Jan 20 & $8: 34$ & Vel & $(-2 / 3)$ & Nina $(? / 3)$ & resting & unsuccess $^{b}$ & \\
\hline \multicolumn{9}{|c|}{$\begin{array}{l}\text { "Days from LH surge checked by using urinary test strip / swelling size (1: detumescent; } 2 \text { : } \\
\text { slight tumescent; 3: maximum tumescent). " "?" represents that LH surge was not checked. }\end{array}$} \\
\hline
\end{tabular}

also observed to perform GG rubbing, but the variety of positions they exhibited were different from those exhibited by bilias ${ }^{4}$. Among wild chimpanzees, we observed GG rubbing at the Mahale Mountains National Park, Tanzania and Bossou, Guinea. Here, we present the first description of GG rubbing by wild chimpanzees.

\section{Methods}

Behavioral observations were conducted from August to November 2003 at Mahale by KZ and from December 2001 to March 2002 at Bossou by SF. KZ followed one of nine focal chimpanzees (P. t. schweinfurthii) on each day and recorded their body contacts with other chimpanzees. SF followed one of four focal females (P. t. verus) on each day and recorded their social interactions.

\section{Observations}

Case 1: GG rubbing of Mahale chimpanzees

On September 14, 2003, KZ followed a 7-yearold female named Athena. Her small sexual skin had not shown swelling. At 11:09:38, when
Athena was resting on the ground, Ruby, an adult female with swollen sexual skin, approached and lay laterally behind Athena. Then Athena mounted Ruby and shook her hip against Ruby' s sexual skin (but Athena's sexual skin did not touch Ruby's) and groomed Ruby. At 11:10:23, after Athena shook her hip again, she slightly stood up and rubbed her sexual skin against Ruby'
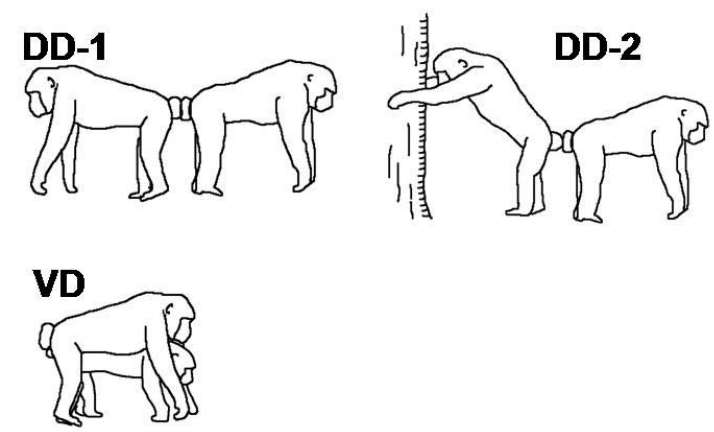

Fig. 2. GG rubbing positions of Bossou chimpanzees. DD-1: dorso-dorsal position in which females stand opposite each other with four limbs on the ground: DD-2: dorso-dorsal position in which a female stands on two legs, placing hands on a tree trunk for support; VD: ventro-dorsal position. 


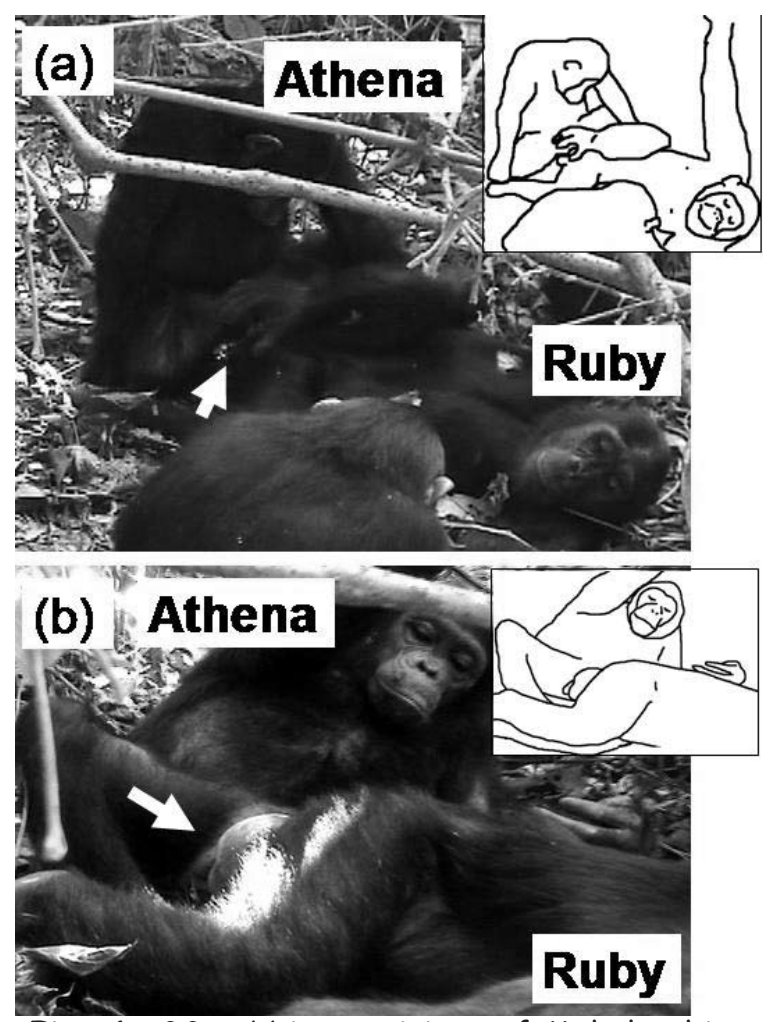

Fig. 1. GG rubbing positions of Mahale chimpanzees. (a) Position 1: Athena is sitting and Ruby is lying laterally. (b) Position 2: Athena is lying on her back and Ruby is lying laterally. Athena moves her hips but Ruby does not.

$\mathrm{s}$ on a front-back axis (Position 1, Fig. 1a). At 11:10:51, Athena lay on her back and rubbed her sexual skin against Ruby's (Position 2, Fig. 1b). Ruby did not shake her hip, but detached it slightly from Athena's. Athena also inspected the sexual skin of Ruby by gazing at it and licking it. KZ observed Position 1 once and Position 2 twice.

\section{Case 2: GG rubbing of Bossou chimpanzees}

SF observed 12 successful and 5 unsuccessful cases of GG rubbing during $556 \mathrm{~h}$ of observation (Table 1). The successful cases were classified into three types of positions (Fig. 2). They occurred in 3 pairs (Vel \& Yo, Vel \& Nina, and Vel \& Vuavua). All females were adult (Vel, Yo, Nina and Vuavua were 42, 40, 47 and 10 years old, respectively) and had experienced parturition. Females engaged in GG rubbing in the dorsodorsal position in 9 cases and in the ventro-dorsal position in 3 cases. In the unsuccessful cases, a female attempted to perform GG rubbing but the other female did not respond to the solicitation.

\section{Discussion}

The frequency of GG rubbing among wild chimpanzees, three bouts during a four-month observation at Mahale and 12 bouts during $556 \mathrm{~h}$ of observation at Bossou, is lower than that among captive animals, e.g. 310 bouts during $71 \mathrm{~h}$ of observation reported by Anestis ${ }^{4}$. GG rubbing among the chimpanzees of Mahale was observed only once by T. Nishida (personal communication), but had not been described because it was not as established as among bilias or captive chimpanzees. In spite of the infrequency of this behavior, five positions of GG rubbing were observed. Among bilias, the ventro-vental position was reported as a typical one ${ }^{1,2}$, while among captive chimpanzees, the ventro-vental, ventrodorsal and dorso-dorsal positions, as well as the ventro-dorsal-like position where the mountee lay on her side, were reported ${ }^{4}$. Among wild chimpanzees, we did not observe the ventrovental position but did observe the dorso-dorsal position, in which a female stood in a bipedal position with the support of a tree trunk (DD-2). Five hypotheses on the function of GG rubbing have been proposed: reconciliation, mate attraction, tension regulation, expression of social status, and social bonding ${ }^{5}$. The small amount of data from our observations precludes the possibility of testing these hypotheses exhaustively, but our results do suggest that GG rubbing did not occur to release tension. In our observations, GG rubbing occurred when chimpanzees were resting $(3 / 3$ in Case 1 and 2/12 in Case 2) and moving (9/12 in Case 2) but rarely occurred during feeding (1/12 in Case $2)$. In addition, no conflict was observed among the chimpanzees engaged in this behavior. It is still unclear whether GG rubbing provides a mechanism to attract mates. When Vel and Nina engaged in GG rubbing (No. 15 in the table), the alpha male of the group disturbed their GG rubbing by shaking a branch at a distance, which, however, did not result in 
heterosexual copulation. Because Nina kept trying to engage in GG rubbing with Vel (No. 16 and 17) after the male's intervention, Nina appeared to have more interest in GG rubbing with Vel than in copulation with the male. Anestis ${ }^{4}$ indicated that GG rubbing could occur with higher probability as the degree of bonding between female chimpanzees was higher. In Case 2, GG rubbing occurred in particular pairs, including a mother and her daughter, among 9 adult females of the group; these pairs had high affinity in the party composition ${ }^{6}$. The data supported the hypothesis that GG rubbing reinforces or at least reflects social bonds.

Interest in another female's swollen sexual skin might cause GG rubbing among wild chimpanzees. In Case 1, Athena gazed and licked the swollen sexual skin of Ruby. Another time, Athena was also observed to investigate her own sexual skin. Athena might perform GG-rubbing to simultaneously fulfill both her interest in the other's swollen sexual skin and her interest in her own immature sexual skin. In Case 2, Vel was involved in all interactions and reached maximum swelling when she GG-rubbed. The initiator of GG rubbing might be interested in the swollen sexual skin of the recipient (Vel) and thus act upon her interest by rubbing her own sexual skin against that of the recipient (Vel).

This study was supported by the Basic Research Fund (\#111111 to T. Nishida) and the Grant for the Biodiversity Research of the 21 st Century COE (A14).

\section{References}

1. Savage-Rumbaugh ES, Wilkerson BJ 1978. Sociosexual behavior in Pan paniscus and Pan troglodytes: a comparative study. J Hum Evol 7: 327-344.

2. Kano T 1980. Social behavior of wild pygmy chimpanzees (Pan paniscus) of Wamba: A preliminary report. J Hum Evol 9: 243-260.

3. Kuroda S 1980. Social behavior of the pygmy chimpanzees. Primates 21: 181-197.

4. Anestis SF 2004. Female genito-genital rubbing in a group of captive chimpanzees. Int J Primatol 25:477-488.

5. Hohmann G, Fruth B 2000 . Use and function of genital contacts among female bonobos. Anim Behav 60: 107-120.

6. Sakura O 1994. Factors affecting party size and composition of chimpanzees (Pan troglodytes verus) at Bossou, Guinea. Int J Primatol 15: 167-263. 